\title{
A note on mental content in the Causal Theory
}

\author{
JP Smit \\ Department of Philosophy, Stellenbosch University, Private Bag X1, 7600 Matieland, South Africa \\ E-mail: jps@sun.ac.za
}

\begin{abstract}
Kripke's causal theory requires that downstream users of a name must have the intention to use the name in the same way that upstream users did. Kripke, however, has demonstrated no need for this requirement qua independent condition. He is antecedently committed to a distinction between baptismal use and downstream use. Any plausible construal of this distinction will block the problem that this condition is supposed to solve.
\end{abstract}

Kripke's basic theory of the reference of names is that a name $N$ refers to the individual baptised $N$ at the origin of the causal chain for $N$. The simplicity of this theory is somewhat misleading as Kripke also requires that the causal chains in question must be "of the required type" (1981:96n). He explains this condition by saying that "[w] hen the name is "passed from link to link' the receiver of the name must, I think, intend when he learns it to use it with the same reference as the man from whom he heard it" (Kripke 1981:96). Call this the Consistent Reference Intention (CRI) Condition. The need for some such condition is generally affirmed in contemporary expositions of Kripke's work, although doubts about exactly how it is supposed to be formulated do surface ${ }^{1}$.

The CRI Condition implies that the causal theory is not purely externalist, i.e. the theory does not make reference completely independent of mental content. There is another potential source of mental content in the causal theory, namely the need to explain what a "baptism" consists in and the attendant need to distinguish baptismal use from the downstream use of a name. Kripke's brief remarks indicate that he views the CRI Condition as a requirement that arises independently from the need to explain what a "baptism" consists in 2 . I will argue that Kripke has demonstrated no need for the CRI Condition qua independent condition. Any viable notion of 'baptism' will block the problem that the CRI Condition is supposed to resolve. This implies that Kripke's arguments do not force the adoption of one explicit source of mental content, namely the CRI Condition, and one potential source of mental content,

\footnotetext{
${ }^{1}$ See, for instance, Soames (2003:365) and Speaks (2010). Speaks explicitly raises the issue discussed in this paper, namely whether such use of intentions renders the causal theory a mentalist theory.

2 This can be seen from Kripke's (1981:97) claim that his theory twice presupposes the notion of 'reference', once in the CRI condition and once in the notion of 'baptism'.
} 
namely the notion of a 'baptism'. Rather, he has only demonstrated the need for the latter (potential) source of mental content.

Kripke (1981:96) originally introduces the CRI Condition in order to deal with the case of a language user, call him "Bob", who has heard the name "Napoleon" and decides to use it as a name for his pet aardvark. In such a case, the worry is that there is a causal link stretching back from such a user to the baptism of the famous statesman. This would seem to imply that Bob's use of "Napoleon" refers to the statesman. The CRI Condition, however, is not satisfied by Bob's use of "Napoleon" and hence Kripke is able to block the implication that Bob's use of the name refers to the statesman ${ }^{3}$.

There is a simpler, Kripkean way of dealing with the above concern. Kripke's theory is committed to a basic distinction between the baptismal use and the downstream use of a name. His causal theory only applies to downstream, non-baptismal usage. Kripke (1981:96), however, construes the case described above as that of a user who consciously decides to use the name "Napoleon" as a name for an aardvark. Now, if anything counts as a baptism, then this does. Bob's act of deciding to call his aardvark "Napoleon" is a paradigm of baptismal usage, despite the fact that Bob used an already existent phonetic-orthographic type to baptise his aardvark. This means that Bob's use of "Napoleon" is not a downstream use at all and hence the causal theory does not apply. Therefore, the main problem that the CRI Condition is supposed to resolve does not arise, as there is no temptation to say that Bob's use of "Napoleon" refers to the statesman.

Any plausible construal of baptismal usage will surely yield the result that Bob's use of "Napoleon" was a baptismal use of an existing phonetic type. It could, of course, turn out that the distinction between a baptismal use and a downstream use depends on something like the CRI Condition, i.e. on whether the speaker intended to use the name as a previous user did. It could even turn out that a baptismal use just is the use of a name without satisfying the CRI Condition, and that downstream use just is the act of using a name in accord with the condition $^{4}$. If this is indeed the case, then Kripke effectively imposed the same requirement twice. But, however one may think about baptisms, it should be clear that Kripke's main argument does not succeed in motivating the need for the CRI Condition qua independent condition.

Kripke (1981:97) goes on to parenthetically suggest that "perhaps it is some such failure to keep reference fixed which accounts for the divergence of present uses of 'Santa Claus' from the alleged original use". Assume, for the sake of the argument, that "Santa Claus" originally

\footnotetext{
${ }^{3}$ This problem should not be confused with the general problem of a language user using one phoneticorthographic type to refer to distinct individuals, where both such uses are straightforward downstream uses. It should also not be confused with the "Newton"/"George Smith" case (Kripke 1981:95). That Kripke does not use the CRI Condition to resolve the latter case can be seen from his statement that such cases cast doubt on the sufficiency of the conditions, including the CRI Condition, that he mentions explicitly (Kripke 1981:97).

${ }^{4}$ Something like this moral could be drawn from Sainsbury (forthcoming). Sainsbury considers how names are to be individuated. He answers that names should, in part, be individuated in terms of the originating events that gave rise to them. He explains that the difference between an originating use and a non-originating use concerns whether the given use deferred to an earlier use or not. It is natural to interpret this as saying that downstream use is deferential use, and that baptismal use is non-deferential use. Deferential use, in turn, is very close to Kripke's CRI Condition, i.e. use that aims to accord with prior use. In this way, the construal of downstream use and satisfying the CRI Condition come very close to being the same thing.
} 
referred to a certain historical saint, but no longer does so. On this assumption, we can distinguish between two possibilities based on whether or not the change in the use of "Santa Claus" was due to a baptismal use of the pre-existing phonetic type "Santa Claus". Recall that Kripke's theory relies on the distinction between baptismal use and downstream use and so he is antecedently committed to drawing this distinction in a way that settles the matter. If the change was due to an act of baptism that uses a pre-existing phonetic type, then the "Santa Claus" case is similar to the "Napoleon" case and hence there is no problem for the CRI Condition to resolve. In Kripke's theory, any subsequent downstream uses of "Santa Claus" then refer unproblematically to the fictional entity 5 .

If the change in referent was not due to an act of baptism, then the situation is a lot more problematic. It would, in effect, make the case of "Santa Claus" a case of unwitting reference change of the type first pointed out by Evans (1982:301). However, if the "Santa Claus" case is indeed this type of case, then the CRI Condition is, at best, yet to earn its keep. Such cases are widely considered to be a major problem for Kripke's theory and it is far from clear, as Kripke (1981:163n) acknowledges, how the CRI Condition is supposed to aid in resolving them. Kripke himself does not originally adopt the CRI Condition in order to deal with such cases, nor does he claim that there is compelling evidence that such cases force us to adopt it.

Ultimately, it may turn out that we need to adopt the CRI Condition to deal with cases of unwitting reference change. On the other hand, it may also turn out that the CRI Condition is irrelevant to such cases, or that they can also be resolved by an expanded conception of 'baptism', or, as some have claimed, that they show the need to replace the notion of 'baptism' with a notion like 'multiple grounding' (Devitt 1981). Another possibility could be that the antecedent needs to specify what the downstream use of the same name consists in. This could result in the need to provide a standard for the individuation of names that may serve to distinguish uses of phonetic types, such as "Santa Claus", in such a way as to solve our problem. None of these latter options give rise to an obvious need to commit to the CRI Condition. This is especially so if this condition is treated, as Kripke does, as a constraint that is independent of the need to explain the notion of a 'baptism' or the related notion of a 'downstream use'.

It should be clear that the adoption of the CRI Condition cannot, at least at present, be motivated by such Evans-style cases of unwitting reference change. We simply do not have any evidence that the CRI Condition is of use in resolving cases like "Santa Claus", "Madagascar", etc. As it is clear that the CRI Condition is not needed to deal with cases like "Napoleon", Kripke's introduction of the CRI Condition, and hence explicit introduction of mental content into the causal theory, is unmotivated.

\footnotetext{
${ }^{5} \mathrm{I}$ am ignoring problems concerning reference to fictional entities as this matter is a mere artifact of the example under discussion.
} 


\section{References}

Devitt, M. 1981. Designation. New York: Columbia University Press.

Evans, G. 1982. In J. McDowell (ed.) The varieties of reference. New York: Oxford University Press.

Kripke, S. 1981. Naming and necessity. Oxford: Blackwell Publishing.

Sainsbury, M. 2014. The same name. Erkenntnis (forthcoming).

Soames, S. 2003. Philosophical analysis in the twentieth century, Volume 2: The age of meaning. Princeton: Princeton University Press.

Speaks, J. 2011. Theories of Meaning. In E. Zalta (ed.) The Stanford encyclopedia of philosophy. Available online: http://plato.stanford.edu/archives/sum2011/entries/meaning/ (Accessed 17 June 2013). 